\title{
Application of systemic-structural activity theory to the design of BOTs and Al software
}

\author{
Inna Bedny ${ }^{1}$ (D)
}

Received: 30 July 2020 / Accepted: 26 January 2021 / Published online: 19 February 2021

(C) The Author(s), under exclusive licence to Springer Nature Switzerland AG part of Springer Nature 2021

\begin{abstract}
Today, artificial intelligence (AI) and BOTs (build-operate-transfer) transform our individual lives and businesses. Some authors even claim that this is the era of intelligence in machines. AI and BOTs are developed to mimic various human behaviors. The Systemic-Structural Activity Theory (SSAT) is the framework that offers numerous methods of analyzing and optimizing human performance and reducing the number of errors. This paper focuses on how the SSAT methodology can be utilized to develop AI and BOTs. The SSAT analysis of the tasks, their design, and testing can be improved via building a human algorithm of the task performance. Such analysis allows users to choose the most efficient method of task performance that can then be applied to the development of an AI or a BOT. This paper discusses the examples of BOT development and demonstrates the capabilities, utilization, and future applications of the SSAT framework.
\end{abstract}

Keywords Artificial intelligence (AI) · BOTs (build-operate-transfer) · Systemic-Structural Activity Theory (SSAT) · Task analysis $\cdot$ Efficiency $\cdot$ Productivity

\section{Introduction}

To stay competitive and increase productivity, companies are always looking for new tools and technologies. Such technologies as AI and BOTs are two that have currently been implemented to carry out repetitive and mundane tasks. An Internet BOT, in its most generic sense, is software that performs an automated task over the Internet. More specifically, a BOT is an automated application used to perform simple and repetitive tasks that would otherwise be time-consuming, mundane, or impossible for a human to perform.

In this paper, we consider some of such repetitive tasks and the issues that the software developers face when they work on designing BOTs for their replacements.

With the waterfall model in place, software testing was mostly taken up at the end of the software development life cycle (SDLC). This sort of testing at the last phase of SDLC led to many missed project timelines and also adversely affected development costs. SSAT offers tools that keep an

Inna Bedny

innabedny@gmail.com

1 Information Technology Department, United Parcel Service, Parsippany, NJ, USA emphasis on enhancing the efficiency of the design process, reducing the number of SDLC, and saving valuable time and resources.

Here, we describe the study conducted when a BOT was needed to replace the procedure that is performed in the Finance and Accounting (FA) department. The company uploads the deposits to the bank database, and then, the bank and company keep track of the company accounts.

The specialists in the FA department log into the bank system and create the report by account and month totals every week, then create the report for the same accounts and time periods using the company database. Their task is then to compare the totals in these two reports to make sure there are no discrepancies in the amounts.

The BOT should be able to perform this task, and if any discrepancies are found, the BOT should be able to notify the FA specialists by sending emails to the list of account managers. These emails will include information on which accounts and time period numbers in the reports do not match and the difference in totals (both negative or positive).

We will show how the process of transferring human tasks into a BOT has been conducted, what issues the software designers faced during this process, and how the application of the SSAT approach and methods can improve the result of such an undertaking. 
We also discuss several papers on $\mathrm{AI}$ and BOT projects and demonstrate how materials published in our latest book (Bedny and Bedny 2018) can be applied to some of the issues discussed in these publications and the task at hand.

\section{Literature review}

Our analysis of the publications shows that the development of AI and BOTs is widely studied from numerous perspectives.

For example, in one such study, the authors developed a model to examine the incentives, efficiency, and regulation in BOT contracts (Qiu and Wang 2011). The efficiency of the BOT projects in the contracts with price regulation is discussed, emphasizing the importance of achieving the full efficiency of the project. Such efficiency can be achieved only by means of the user-centered design.

The authors of the paper, "Modelling human cognition of abnormal machine behavior," decided to utilize the three-level SA (Situation Awareness) Theory as a framework for their study (Illankoon et al. 2019). The interesting aspects of this study touch on the idea of two permanent operating information processing systems which are intuitive and analytic. The study could be further developed using our publication that offers the self-regulation model and raises the awareness of the difference between such notions as meaning and sense, and complexity and difficulty (Bedny and Bedny 2019).

Another compelling paper that gives a new perspective on an important issue of human-machine interaction has been published by Suhir and Paul (2019). The issues that arise with human preparedness for operating the automated vehicles present an important and timely topic, and the authors give a new perspective on this issue.

According to the practice and the experiences collected in the Chinese BOT project that took place at the Laibin B power plant, the minimum electricity price can be obtained by improving the economic efficiency of the project. The emphasis here is on the capacity and efficiency of the BOT developer company (Zhao et al. 2013). The researchers who conducted the interviews concluded that the business operation capacity of the developer is critical to the success of such BOT projects.

Follow-up studies conducted at the warehouses show that AI robots are beginning to replace the heavy burden of human work in large numbers (an apparent trend) and that the human order picking strategy has played a substantial role in improving process efficiency. On the other hand, the surge in Internet purchases makes the warehouse management systems the front and center of today's industrial settings. Our 2018 book (Bedny and Bedny 2018) presents an extensive study of the efficiency of the receiving orders operation at the warehouse. It demonstrates how the application of SSAT can improve efficiency and reduce the complexity of the task performance.
Some results of this research are discussed below. The SSAT methodology can be applied to the design of the BOTs that replace rule-based repetitive tasks.

In the paper dedicated to the improvement of the efficiency of the warehouse management system (Boysena et al. 2017), a new pick-to-light method based on the mutual behavior analysis of humans and robots applying the fuzzy set theory to an AI robot is proposed. The described method attempts to apply an ergonomic approach to robots' efficiency to make orderpicking path planning more effective and precise, which would reduce the picking flow time and lower the human physical and mental load. An example considered in this study illustrates that the proposed method can improve the productivity and ergonomic quality of the pick-to-light sequence planning. The AI-based robotic equipment and the computer-aided picking system, which is driven by robots, has a major impact on close collaboration between material handling devices, people, and the environment. It should be taken into account that to satisfy human work and quality of life, the warehouse manager has to balance the workload with time constraints.

In their 2020 publication, Canhoto and Clear point out that if businesses wish to benefit from using AI and BOT tools, they need a good understanding of these tools. The framework presented in this article states that one should look beyond the type of algorithm used and cost-benefit calculations to avoid common pitfalls and create true value for the businesses (Canhoto and Clear 2020).

$\mathrm{AI}$ is now widely used in medicine, and most recently, it has been utilized in our fight with COVID-19: to analyze Internet communication to detect the spread of the virus, to find drugs that target the virus, to identify the existing drugs that can help the patients at various stages of the disease, to identify the structure of COVID-19, to detect the outbreak and spread of other new diseases, to spot signs of a COVID-19 infection in medical images, to monitor how the virus and lockdown is affecting mental health, and to organize research results from scientists all over the world (Swayamsiddha and Mohanty 2020; Ting et al. 2020; Mohanty et al. 2020; Scudellari 2020; Mak and Pichika 2019; Sipior 2020).

\section{Method}

For this case study, we have chosen the development of the BOT, the function of which should be to replace the repetitive and routine task of verifying financial reports and sending emails reporting the results of the verification.

The study is based on the analysis of the questionnaire given to the three specialists with different levels of experience who perform the task of comparing the company bank reports after the company submits its revenue to the bank database. 
Based on their answers, the BOT was needed to replace this rule-based task. The BOT would log in to each system, produce the reports, download them, and then compare them by mimicking the task performed by specialists. The last function of the BOT would be to email discrepancies, if any, to the selected list of managers in the Finance and Accounting department.

Table 1 contains the fragment of the questionnaire given to three specialists of the Finance and Accounting department.

The analysis of the three specialists' (who have various levels of work experience) responses shows that they all had some deviations in their methods of this particular task performance.

Specialist \#1 had the most experience performing this task. We would call him/her the perfect user. This user performed the task very fast and efficiently and had a lot to say about the abnormal cases. On the other hand, the analysis of his answers to the questionnaire compared to the other two specialists' answers showed that she/he skipped a lot of details that would be essential for the BOT development. It is our observation that the perfect users who perform the task routinely internalize a lot of important details of their task performance.

Surprisingly, the answers of the least experienced Specialist \#3 were the most thorough ones because this person was still learning the process and paid the most attention to all of its details. Task acquisition appears to be the optimal phase to study the task and to determine the optimal ways of its performance. The software developers usually rely on the answers given by the most senior task performers which leads to many issues with the software design. Given three different answers acquired by the questionnaire, how would the BOT designer decide which method of performance to follow to create the most efficient BOT?

Figure 1 depicts the fragment of the questionnaire filled by Specialist \#1. It is evident that the information is not well
Table 1 Fragment of the questionnaire

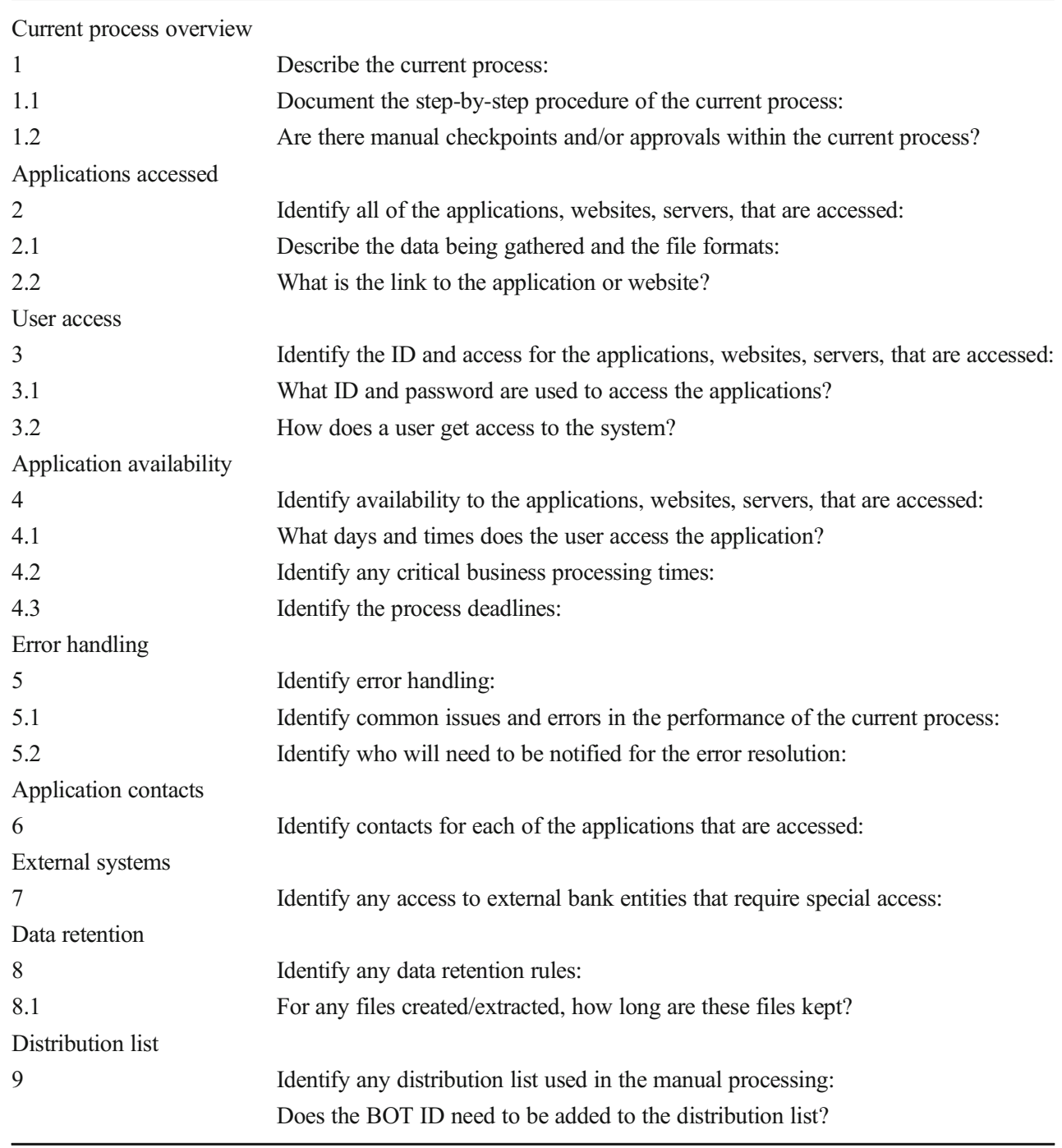


Fig. 1 Fragment of the questionnaire, filled by Specialist \#1

\section{Click on "Cancelled Bar Code Audit Report"}

6. Selection criteria will be repeated for Region $03,07,10$ and 22

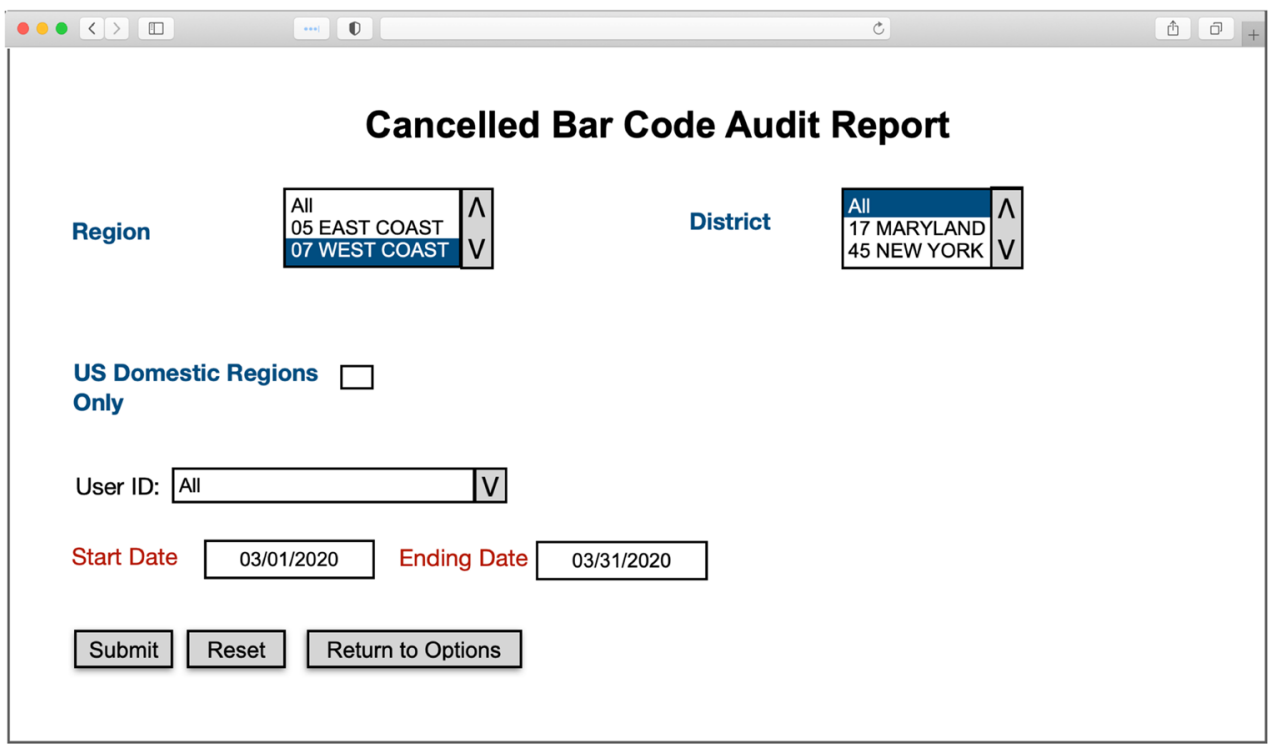

7. First start with the "03" Region -> District criteria select "All" For region 22, only select 65

8. Start Date will be first day of the month and Ending Date will be the last day of the month - calendar days, e.g.: we choose 03/01/2020 and $03 / 31 / 2020$ when we prepare the journal on 4/1/2020 (1st business day)

\section{Click on "Submit"}

\section{The report below will appear.}

structured and it would take a long time to organize it in a strict enough way so the task can be coded into a BOT.

Figure 2 shows the resulting BOT.

We suggest using SSAT as the framework, which offers detailed procedures for analysis and comparison of the different methods of task performance (Bedny and Bedny 2018).
The application of this methodology takes some time, but it allows us to choose the most efficient method of task performance. The initial investment in the efficiency of the software design is the right step at the early stages of the SDLC due to its expense and its expected repeated utilization over time.

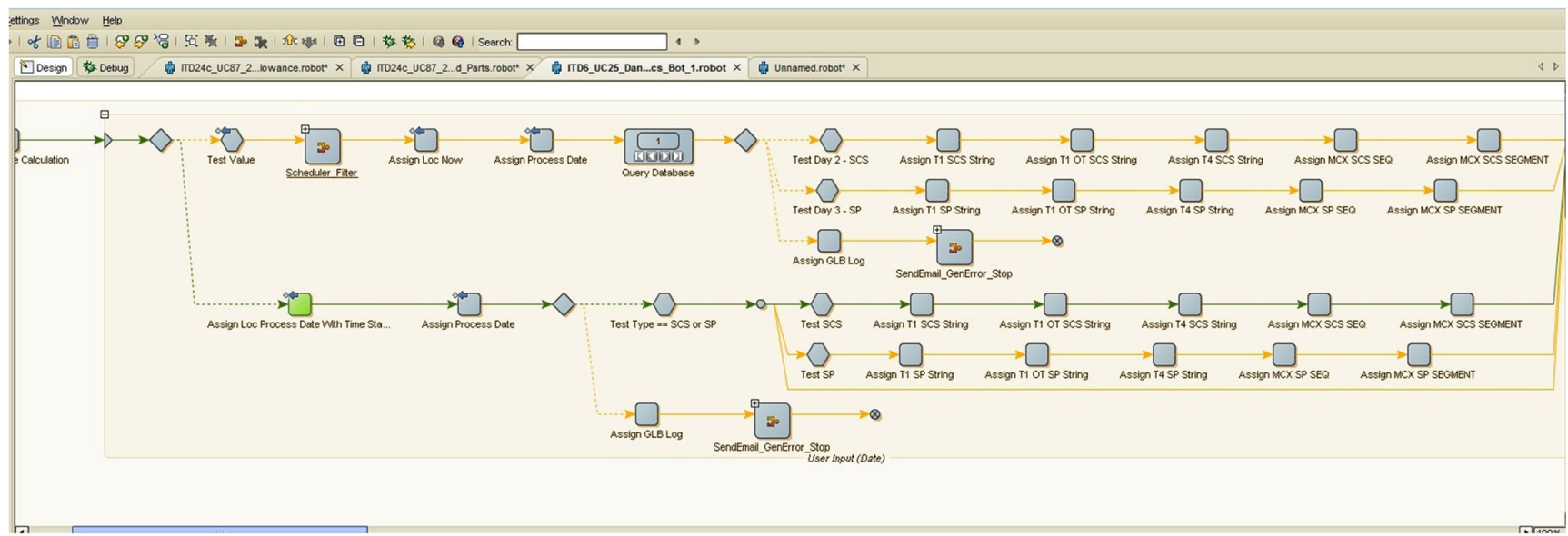

Fig. 2 Fragment of the coded BOT 


\subsection{Application of SSAT to the improvement of the software design}

Multiple authors demonstrated the application of SSAT to the analysis of the software design and showed that it leads to a much more efficient and user-friendly product.

It is beneficial to analyze the users' behavior at the earliest phase of the project that should form the context for the subsequent software design.

Harris (2005) stated in his study that SSAT sees human activity as a logically organized system of mental and behavioral actions. This is where cognition, behavior, and motivation are integrated and organized by mechanisms of selfregulation toward achieving conscious goals.

SSAT streamlines and organizes the IT design process and makes it efficient.

The following are some of the methods of the SSAT analysis.

\subsection{Morphological analysis}

The main purpose of morphological analysis is to transfer the ambiguous qualitative description of a complex system into a clearly structured one. The morphological analysis of human activity was originally developed by Gregory Bedny within the SSAT framework (Bedny 1981; Bedny 2015; Bedny et al. 2015). Rigorous verbal description is followed by presenting human activity as an algorithm. In the below examples, we show how such human algorithms are structured for various tasks.

Table 2 depicts the human algorithm of the performance of the task "Check a Digital Indicator."

In the following tables, $O^{\varepsilon}$ represents a motor or behavior action, $O^{\alpha}$ depicts a perceptual or any cognitive action, and $l$ is called logical condition. Logical conditions signal that the decision is made here and that they define the order of the following actions.

Table 3 presents the algorithmic description of the task when a driver has to stop the car unexpectedly.

Tables 2, 3, and 4 are examples of presenting human performance of the task as an algorithm. Such presentation allows

Table 2 Human Algorithm for the Task "Check a Digital Indicator"

Members of the Description of the members of the algorithm algorithm

\begin{tabular}{ll}
\hline$O_{1}^{\alpha}$ & Take reading from digital indicator \\
$l_{1} \uparrow$ & $\begin{array}{l}\text { If an even number is shown, then perform } O_{2}^{\varepsilon} \text {. If an } \\
\text { odd number is displayed then perform } O_{3}^{\varepsilon}\end{array}$ \\
$O_{2}^{\varepsilon}$ & Turn two-positioned switch up \\
$\downarrow O_{3}^{\varepsilon}$ & Turn two-positioned switch down \\
\hline
\end{tabular}

the reader to understand the structure and logic of the task performance, to calculate the time needed to complete the task, and to identify the areas where the errors occurred due to the task complexity. The last are the areas where the improvement of the conditions for the task performance is the most critical.

The following Tables 5 and 6 are the fragments of tables created when we analyzed the performance of three different versions of the same inventory receiving task in the warehouse management system (Bedny and Bedny 2018). This study also included the tables depicting the performance of this task before and after implementation, as well as the enhancements of the software utilized in this task.

On the one hand, the performance time of each element of the task allows us to determine the performance time of the whole task, and on the other hand, to estimate the reliability and complexity of the task performance.

The performance time of this task before the implementation of the software enhancement was $39.18 \mathrm{~s}$, and after implementation, it dropped to $33.42 \mathrm{~s}$. It is also important to mention that there was a reduction of errors after the memory workload had been reduced.

The complete description of this method and examples of human algorithms for both computer-based and computerized tasks can be found in Bedny and Bedny (2018).

The application of this SSAT algorithmic analysis at the design stage of the BOT development would allow choosing the most reliable and efficient method of the process flow, as well as to uncover the omitted and inefficient parts of the existing process. Such early detection would save time and money by making the design process efficient at the initial stages of the BOT development.

\subsection{Quantitative analysis}

Human activity is a complex structure that unfolds in time. This makes its quantitative analysis rather difficult to perform. Choosing the adequate units of measurement was one of the main obstacles in the complexity evaluation of the task performance. SSAT suggests using the complexity of the time intervals of human activity to evaluate the complexity of task performance.

Complexity and reliability assessment of the task performance would facilitate choosing the best method of task performance that can be then coded into a BOT. Such rigorous analysis takes time, but considering that some BOTs would be utilized repeatedly for a number of years, choosing the best design is a must. This method also permits future improvements to be predicted and to be one step ahead of the user requirements.

Tables 5 and 6 have been used to calculate the measures of the task complexity and to compare the complexity of the task 
Table 3 Algorithmic description of task when a driver stops a car in an emergency situation.

\begin{tabular}{|c|c|c|c|}
\hline \multirow{2}{*}{$\begin{array}{l}\text { Members of } \\
\text { algorithm }\end{array}$} & \multicolumn{2}{|l|}{ Description of members of the algorithm } & \multirow{2}{*}{$\begin{array}{l}\text { Performance } \\
\text { time }(\mathrm{sec})\end{array}$} \\
\hline & Technological units of analysis & Psychological units of analysis & \\
\hline$O_{1}^{\alpha \text { th }}$ & $\begin{array}{l}\text { Mental awareness "This rural road had a small slope and my car } \\
\text { moves too fast" }\end{array}$ & $\begin{array}{l}\text { Simple verbally logical thinking action based } \\
\text { on visual information }\end{array}$ & 0.85 \\
\hline$l_{1} \uparrow$ & I need to push the brake to slow down & Decision-making action at verbal logical level & 0.3 \\
\hline$\downarrow \mathrm{O}_{2}^{\varepsilon}$ & Driver pushed the brake two times & Behavioral action & 2.29 \\
\hline $\mathrm{O}_{3}^{\text {th }}$ & Mental awareness that car keeps moving with the same speed & $\begin{array}{l}\text { Simple verbally logical thinking action based } \\
\text { on visual information }\end{array}$ & 0.75 \\
\hline$O_{4}^{\text {th }}$ & $\begin{array}{l}\text { Mental awareness of the situation "rural road has a small slope and } \\
\text { my car brakes are broken" }\end{array}$ & Simple verbally logical thinking action & 0.35 \\
\hline$O_{5}^{\text {th }}$ & $\begin{array}{l}\text { Mental awareness of the situation "I need to move my car to the } \\
\text { edge of the road and stop" }\end{array}$ & Simple verbally logical thinking action & 0.35 \\
\hline$O_{6}^{\alpha}$ & $\begin{array}{l}\text { Unexpectedly, the driver sees the oncoming car at a relatively close } \\
\text { distance }\end{array}$ & Simultaneous perceptual action & 0.4 \\
\hline$O_{7}^{\alpha}$ & $\begin{array}{l}\text { Driver sees a heap of gravel ( } \approx 5 \text { feet wide) at the right side of the } \\
\text { road }\end{array}$ & Simultaneous perceptual action & 0.4 \\
\hline$O_{8}^{\text {th }}$ & Heap of gravel can stop my car without damage & $\begin{array}{l}\text { Deductive reasoning (simple verbally logical } \\
\text { action) }\end{array}$ & 5 \\
\hline$l_{2} \uparrow$ & $\begin{array}{l}\text { The driver decides to turn toward the heap of gravel and his car } \\
\text { stops without a strong impact }\end{array}$ & Decision-making action at verbal logical level & 0.3 \\
\hline$\downarrow O_{9}^{\varepsilon}$ & Driver turns cars steering wheel to the right (two short right turns) & Behavioral action & 4 \\
\hline Total time & & & 15 \\
\hline
\end{tabular}

performance before and after implementation of the enhancements.

Table 7 depicts some of the measures of the complexity of the task performance and their values to compare the complexity of the task performance.

The comparison of these measures for the version 1 of the inventory receiving task before and after improvement is given below.

The comparison shows that the enhancement of the software resulted in the reduction of cognitive workload in general and the memory workload in particular.

Such quantitative analysis shows that SSAT allows us to determine the most efficient version of the software design even before its creation.

\section{Discussion}

In this work, we demonstrated the capabilities of SSAT in improving the accuracy and enhancing the efficiency of the design of BOTs in particular and AI in general.

SSAT's consistent and reproducible methods of task analysis and evaluation of task complexity combined with AI can assist in optimizing the software design in several ways: highly accurate human activity analysis, evaluation of the reliability of performance, and assessment of task complexity are just some of its benefits.

AI technology plays an important role in our life. Companies and organizations are in an urgent need of decision-making technologies for a variety of applications.

Table 4 Human algorithm of performing the task of testing the state of equipment in the military settings.

\begin{tabular}{|c|c|c|c|}
\hline $\begin{array}{l}\text { Member of the } \\
\text { algorithm }\end{array}$ & Technological units of analysis & Psychological units of analysis & $\begin{array}{l}\text { Time } \\
(\mathrm{s})\end{array}$ \\
\hline$O_{1}^{\alpha}$ & $\begin{array}{l}\text { Visual perception of three-positioning switch on the right-hand } \\
\text { side panel }\end{array}$ & Sequential perceptual action & 0.55 \\
\hline$O_{2}^{\varepsilon}$ & $\begin{array}{l}\text { Turning of three-positioning switch on the right-hand side } \\
\text { of the panel (move an arm and grasp a switch) }\end{array}$ & Behavioral action & 0.95 \\
\hline ---- ----- & ------- ------- ------ & ------- -------- --------- & --- ---- \\
\hline$O_{5}^{\alpha t h}$ & Interpretation of information about the first subsystem & $\begin{array}{l}\text { Thinking categorization action (the simplest } \\
\text { thinking action performed based on visual } \\
\text { information) }\end{array}$ & 0.30 \\
\hline${ }_{1} l_{1} \uparrow$ & $\begin{array}{l}\text { If subsystem } 1 \text { is blocked, decide to unblock the system } \\
\text { (go to } O_{6}^{\varepsilon} \text { ). If the subsystem is on, check the second } \\
\text { subsystem (perform } O_{9}^{\alpha} \text { ) }\end{array}$ & $\begin{array}{l}\text { The simplest decision-making action with two al- } \\
\text { ternatives }\end{array}$ & 0.30 \\
\hline ---- ---- & ----- ------ ------ & ------ ------- ------ & --- --- \\
\hline
\end{tabular}


Table 5 Algorithmic description of version 1 of inventory receiving task performance before improvement —item is put aside due to unacceptable quantity

\begin{tabular}{|c|c|c|}
\hline Members of the algorithm & Technological units of analysis & Time (s) \\
\hline$\downarrow^{17(2)} \downarrow^{11(2)} \downarrow^{7(2)} O^{\varepsilon}{ }_{17}$ & $\begin{array}{l}\text { Take an item out of the box and return to the computer area (while an operator takes several } \\
\text { steps, his/her right hand releases the item and he/she holds the item only by the left hand). }\end{array}$ & 5.7 \\
\hline$O^{\alpha \mu}{ }_{18}$ & Look at the item number on the physical item and compare it with the item numbers on the screen. & Average time $\approx 6$ \\
\hline$l_{4} \uparrow^{4}$ & $\begin{array}{l}\text { If the item number is on the first page, go to } O^{\varepsilon}{ }_{20} \text {. If the item number is not on the first } \\
\text { page, go to } O^{\varepsilon}{ }_{19}\end{array}$ & 0.3 \\
\hline$O_{19}^{\varepsilon}$ & Press the arrow key (repeat if required) & 0.62 \\
\hline$\downarrow^{4} O \varepsilon_{20}$ & $\begin{array}{l}\text { Put the cursor on the selected line and press ENTER to go to the screen with the } \\
\text { detailed item information }\end{array}$ & 2.64 \\
\hline$O_{21}^{\alpha \mu}$ & Compare received item quantity with PO (purchase order) quantity & 1.64 \\
\hline$l_{5} \uparrow^{5}$ & $\begin{array}{l}\text { If the received quantity and ordered quantity are the same, go to } O_{29}^{\varepsilon} \text { (this output is } \\
\text { performed in other subtasks). If the received quantity is greater or less than the } \\
\text { ordered quantity, go to } O_{22}^{\varepsilon}\end{array}$ & 0.4 \\
\hline$O^{\varepsilon}{ }_{22}$ & Type the received quantity and press ENTER to get a question at the bottom of the screen. & 1.7 \\
\hline$O_{23}^{\alpha 2}$ & $\begin{array}{l}\text { Read the statement: THE RECIVED QUANTITY AND ORDERED QUANTITY } \\
\text { DO NOT MATCH. DO YOU ACCEPT? (YES/NO). Scan and read. }\end{array}$ & 1.14 \\
\hline *** $O^{\mu \mathrm{th}}{ }_{24}$ & Recall instructions and the perform required calculation and estimation & 4.2 \\
\hline$l_{6} \uparrow^{6}$ & $\begin{array}{l}\text { If quantity is not accepted (computer defaults to "N") go to } O^{\varepsilon}{ }_{25} \text { (in this version of the } \\
\text { task, the considered outcome is performed with } P=1 \text { ). Otherwise, go to } O_{28}^{\varepsilon} \\
\text { (this is performed in another version of the task) }\end{array}$ & 1.5 \\
\hline$O^{\varepsilon}{ }_{25}$ & Press ENTER (default is confirmed) & 0.84 \\
\hline$O^{\varepsilon}{ }_{26}$ & $\begin{array}{l}\text { Put the rejected item in the Put-Aside Area. Return to the base unit. } O^{\varepsilon}{ }_{26} \text { includes (1) } \\
\text { left hand grasps the item; (2) operator turns and takes approximately } 6 \text { steps to the } \\
\text { put aside area; move left hand and release an item; (3) operator turns and takes } \\
\text { approximately } 4 \text { steps to the base unit for unpacking }\end{array}$ & 12.5 \\
\hline $\begin{array}{l}\text { Total performance time for } \\
\text { the first version of the task }\end{array}$ & Task of receiving an item ends here & 39.18 \\
\hline$O_{27}^{\alpha}$ & Check if there are other items in the box to receive & 0.72 \\
\hline$l_{7} \uparrow^{7(1-2)}$ & If there are no more items in the box, go to $O_{4,}^{\varepsilon}$ (subtask 0); otherwise, go to $O^{\varepsilon}{ }_{17}$. & 0.3 \\
\hline
\end{tabular}

Table 6 Algorithmic description of version 1 of inventory receiving task after improvement — Item is put aside due to unacceptable quantity

\begin{tabular}{|c|c|c|}
\hline Member of algorithm & Technological units of analysis & Time (s) \\
\hline$\downarrow^{8(2)} \downarrow^{5(2)} O^{\varepsilon}{ }_{11}$ & $\begin{array}{l}\text { Take an item out of the box and return to computer area (while an operator takes several } \\
\text { steps his/her right hand releases the item and he/she holds the item by left hand only). }\end{array}$ & 5.7 \\
\hline$O^{\varepsilon}{ }_{12}$ & Take the barcode scanner and scan the item number (the matching item is highlighted). & 2.9 \\
\hline$O^{\varepsilon}{ }_{13}$ & Hit ENTER to go to the screen with detailed item information. & 0.9 \\
\hline$O^{\alpha \mu}{ }_{14}$ & Compare received quantity with PO (purchase order) quantity. & 1.64 \\
\hline$l_{3} \uparrow^{3}$ & $\begin{array}{l}\text { If the received quantity and ordered quantity are the same, go to } O_{22}^{\varepsilon}(P=0.9) \text {. If the received } \\
\text { quantity is greater or less than the ordered quantity, go to } O_{15}^{\varepsilon}(P=0.1)\end{array}$ & 0.4 \\
\hline$O^{\varepsilon}{ }_{15}$ & Type the received quantity and press ENTER to get a question at the bottom of the screen $(P=0.1)$ & 1.7 \\
\hline$O^{\alpha}{ }_{16}$ & $\begin{array}{l}\text { Read the statement: THE RECIEVED QUANTITY AND ORDERED QUANTITY DO NOT } \\
\text { MATCH. DO YOU ACCEPT? (YES/NO). }(P=0.1) \text {. Scan and read. }\end{array}$ & 1.14 \\
\hline${ }^{*} O_{17}^{\mu \mathrm{th}}$ & Recall instructions and perform required calculation and estimation (quantity and price ratio). & 4.2 \\
\hline$l_{4} \uparrow^{4}$ & $\begin{array}{l}\text { If the quantity is not accepted (computer defaults to "N"), go to } O_{18}^{\varepsilon}(P=0.07) \text {. } \\
\text { Otherwise, go to } O^{\varepsilon}{ }_{21}(P=0.03)\end{array}$ & 1.5 \\
\hline$O^{\varepsilon}{ }_{18}$ & Press ENTER (default is confirmed and after performing $O^{\varepsilon}{ }_{19}$ start working with a new item). $P=0.07$. & 0.84 \\
\hline$O^{\varepsilon}{ }_{19}$ & $\begin{array}{l}\text { Put the rejected item in the Put-Aside Area. Return to the base unit }(P=0.07) \text {. } \\
O^{\varepsilon}{ }_{19} \text { includes (1) left hand grasps an item; (2) an operator turns his/her body and takes } \\
\text { approximately } 6 \text { steps to the put aside area; moves left hand and releases an item; (3) } \\
\text { an operator turns his/her body and take approximately } 4 \text { steps to the base unit. }\end{array}$ & 12.5 \\
\hline $\begin{array}{l}\text { Total performance time } \\
\text { of the first version of the task }\end{array}$ & Task of receiving an item ends here. & 33.42 \\
\hline$O^{\alpha}{ }_{20}$ & Check if there are other items in the box to receive. & 0.72 \\
\hline$l_{5} \uparrow^{5(1-2)}$ & $\begin{array}{l}\text { If there are no more items in the box, go to } O_{4}^{\varepsilon} \text {; otherwise, press } \mathrm{F} 3 \text { to return to the } \\
\text { previous screen and go to } O_{11}^{\varepsilon} \text {. }\end{array}$ & 0.3 \\
\hline
\end{tabular}


Table 7 Measures of complexity of the task performance before and after innovation (fragment).

\begin{tabular}{|c|c|c|c|c|}
\hline $\begin{array}{l}\text { Measure } \\
\text { number }\end{array}$ & Measures & $\begin{array}{l}\text { Time before } \\
\text { innovation (s) }\end{array}$ & $\begin{array}{l}\text { Time after } \\
\text { innovation (s) }\end{array}$ & Psychological meaning \\
\hline 1 & $\begin{array}{l}\text { Task execution time } \\
T=\Sigma P i t_{\mathrm{i}}\end{array}$ & 39.18 & 33.42 & Duration of task performance \\
\hline 2 & $\begin{array}{l}\text { Performance time of all afferent operators } \\
T \alpha=\Sigma P^{\alpha} t^{\alpha}\end{array}$ & 8.78 & 2.78 & $\begin{array}{l}\text { Duration of perceptual } \\
\text { components of the task }\end{array}$ \\
\hline 3 & $\begin{array}{l}\text { Performance time of all thinking operators } \\
T \text { th }=\Sigma P^{\text {th }} t^{\text {th }}\end{array}$ & 4.2 & 4.2 & $\begin{array}{l}\text { Duration of thinking components } \\
\text { of the task }\end{array}$ \\
\hline 4 & $\begin{array}{l}\text { Performance time of all operators that requires } \\
\text { keeping the information in working memory } \\
T w m=\Sigma P_{\mathrm{wm}} t_{\mathrm{wm}}\end{array}$ & 11.84 & 5.84 & $\begin{array}{l}\text { Time for retaining information in } \\
\text { working memory }\end{array}$ \\
\hline 5 & $\begin{array}{l}\text { Performance time of all logical conditions } \\
L_{g}=\Sigma P^{l} t^{l}\end{array}$ & 2.2 & 1.9 & $\begin{array}{l}\text { Duration of decision-making } \\
\text { components of the task }\end{array}$ \\
\hline 6 & $\begin{array}{l}\text { Performance time of all efferent operators } \\
T_{\mathrm{ex}}=\Sigma P_{\mathrm{j}} t_{\mathrm{j}}\end{array}$ & 24 & 24.54 & $\begin{array}{l}\text { Duration of executive } \\
\text { components of the task }\end{array}$ \\
\hline 7 & $\begin{array}{l}\text { Performance time of all cognitive components including } \\
\text { perceptual activity } \\
T \operatorname{cog}=T \alpha+T \text { th }+L_{\mathrm{g}}\end{array}$ & 15.18 & 8.88 & $\begin{array}{l}\text { Duration of all cognitive } \\
\text { components of the task }\end{array}$ \\
\hline 8 & $\begin{array}{l}\text { Fraction of time for afferent operators in the entire task } \\
\text { performance time } \\
N \alpha=T \alpha / T\end{array}$ & 0.22 & 0.08 & Perceptual workload \\
\hline 9 & $\begin{array}{l}\text { Fraction of time for thinking operators in entire task } \\
\text { performance time } \\
N \mathrm{th}=T \mathrm{th} / T\end{array}$ & 0.11 & 0.13 & Problem solving workload \\
\hline 10 & $\begin{array}{l}\text { Fraction of time for logical conditions in the entire task } \\
\text { performance time } \\
N_{l}=L_{g} / T\end{array}$ & 0.06 & 0.06 & Decision-making workload \\
\hline 11 & $\begin{array}{l}\text { Fraction of time for performance of cognitive components of task } \\
\text { to the entire task performance time } \\
N \operatorname{cog}=T \operatorname{cog} / T\end{array}$ & 0.39 & 0.27 & General cognitive workload \\
\hline 12 & $\begin{array}{l}\text { Fraction of time for retaining information in working memory in } \\
\text { the entire task performance time } \\
N w m=T w m / T\end{array}$ & 0.3 & 0.17 & Memory workload \\
\hline
\end{tabular}

SSAT offers advanced methods for the optimization of such technologies.

AI is now used to fight the COVID-19 pandemic allowing it to detect the cluster of cases and to predict where this virus will reappear in the future by collecting and analyzing all previous data.

AI works in a proficient way to mimic human intelligence. It also played a role in the development of a vaccine for COVID-19.

At the next stage of this study, we are going to build three versions of the human algorithm of the task performance for three specialists and compare the complexity and reliability measures to determine which method of this task performance is the most efficient one. Then, the most efficient version of the BOT design can be determined.

SSAT analysis is time-consuming, but its utilization leads to much better results and saves time and money by making the design process an efficient one at its early stages.

The SSAT objects of study can also include webpages, cell phone apps, and AI design.

\section{Conclusion}

To meet today's challenges and to prepare for the future, businesses need AI solutions that integrate them with their infrastructure and data integrity strategy.

SSAT is a high-level generality theory, but at the same time, it offers elaborate methods of task analysis that allow to determine the task complexity and the most efficient methods of human performance. These methods are vital when the repetitive rule-based tasks are replaced with the BOTs. The BOT design can be very efficient when SSAT methods and strategies are applied. The SSAT can be also used when designing more complex AI processes.

AI designers should be open to applying new methods of task analysis that lead to better results.

They might be set in their ways of approaching the process analysis, but when applying SSAT, they would realize that it is an effective tool that allows them to choose the best version of the software.

New methods of quantitative analysis of human activity have been developed within the SSAT framework, and task 
complexity assessment is one of the most important methods of task analysis. Complexity is a multidimensional phenomenon, and it requires multiple measures for its evaluation.

The acquisition stage is the best time for evaluation of task complexity. Studying human performance at this stage can both determine the key points for process improvement and find a way to reduce human errors and process failures.

SSAT is a framework that should be utilized to enhance the digital customer experience, including both front-end services and back-office process optimization.

\section{Declarations}

Conflict of interest The author declares no conflict of interest.

\section{References}

Bedny G (1981) The psychological aspects of time study in vocational training. Higher Education Publisher

Bedny G (2015) Application of systemic-structural activity theory to design and training. Boca Raton, Florida, USA, CRC Press, Taylor and Francis Group

Bedny G, Bedny I (2018) Applied and systemic-structural activity theories. Boca Raton, Florida, USA, CRC Press, Taylor and Francis Group

Bedny G, Bedny I (2019) Work activity studies within the framework of ergonomics, psychology, and economics. Boca Raton, Florida, USA, CRC Press, Taylor and Francis Group

Bedny G, Karwowski W, Bedny I (2015) Applying systemic-structural activity theory to design of human-computer interaction systems. Boca Raton, Florida, USA, CRC Press, Taylor and Francis Group
Boysena N, Briskornb D, Emdec S (2017) Parts-to-picker based order processing in a rack-moving mobile robots' environment. Eur J Oper Res J, Elsevier

Canhoto A, Clear F (2020) Artificial intelligence and machine learning as business tools: a framework for diagnosing value destruction potential, Business Horizons, Elsevier

Harris S (2005) Systemic-structural activity analysis of HCI video data. Hypermedia Research Unit, University of Glamorgan, Wales

Illankoon P, Tretten P, Kumar U (2019) Modelling human cognition of abnormal machine behaviour. Human-Intell Syst Integr 1

Mak K, Pichika M (2019) Artificial intelligence in drug development: present status and future prospects. Drug Discov Today 24(3):773780

Mohanty S, AI Rashid H, Mridul M, Mohanty C, Swayamsiddha S (2020) Application of artificial intelligence in COVID-19 drug repurposing. Diab Metab Syndrom: Clin Res Rev 14(5):1027-1031

Qiu L, Wang S (2011) BOT projects: incentives and efficiency. J Dev Econ 94:127-138

Scudellari M (2020) Five companies using AI to fight coronavirus, IEEE Spectrum. https://spectrum.ieee.org/the-human-os/artificialintelligence/medical-ai/companies-ai-CoV

Sipior JC (2020) Considerations for development and use of AI in response to COVID-19. Int J Inf Manag 55:102170

Suhir E, Paul G (2019) Avoiding collision in automated driving situation. Theor Issues Ergon Sci

Swayamsiddha S, Mohanty C (2020) Application of cognitive internet of medical things for COVID-19 pandemic. Diabetes Metab Syndr 14(5):911-915

Ting D, Carin L, Dzau V, Wong T (2020) Digital technology and COVID-19. J Nat Med 26(4):459-461

Zhao Z, Zuo J, Zillante G (2013) Factors influencing the success of BOT power plant projects in China. Renew Sustain Energy Rev J

Publisher's note Springer Nature remains neutral with regard to jurisdictional claims in published maps and institutional affiliations. 